Provided for non-commercial research and education use. Not for reproduction, distribution or commercial use.

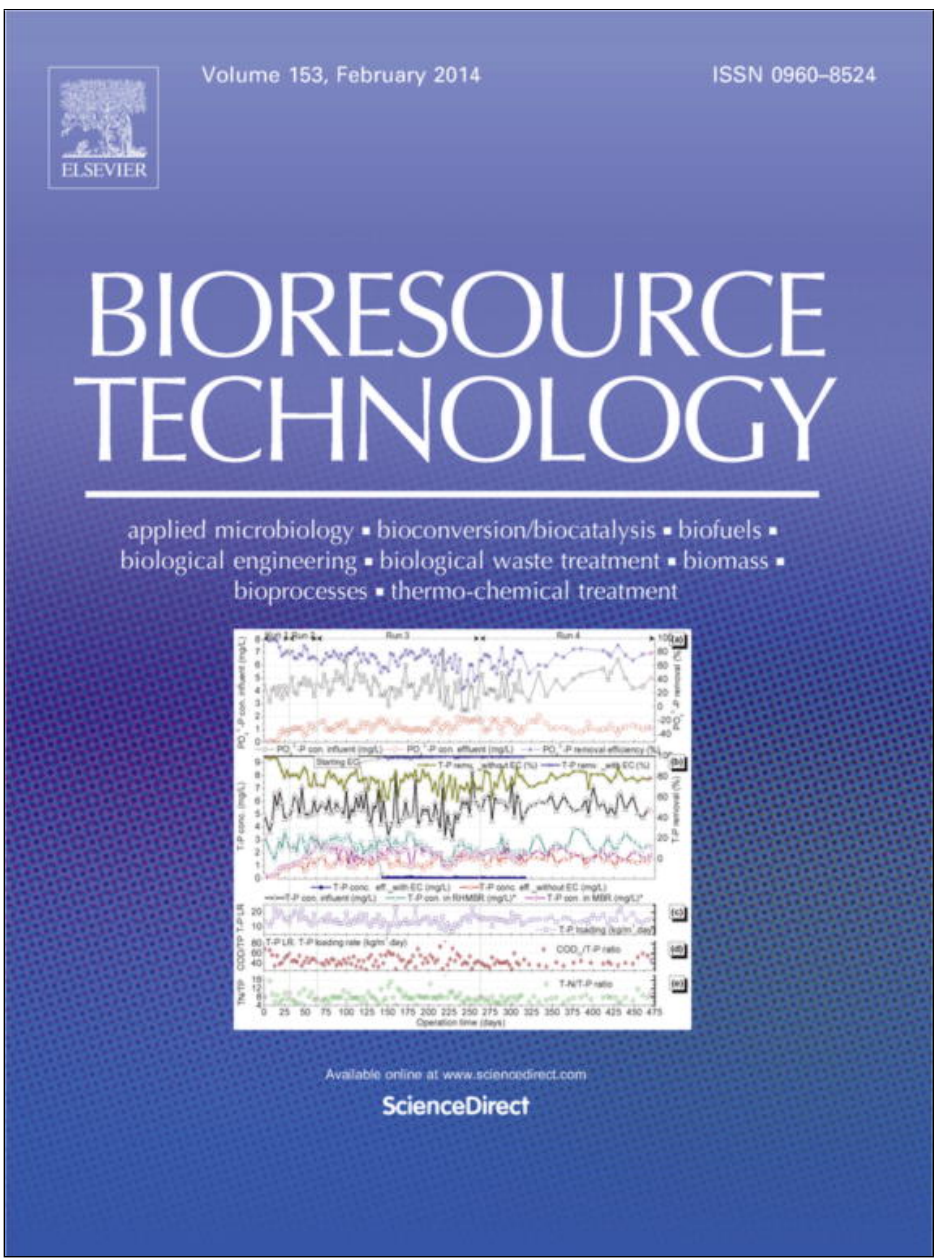

This article appeared in a journal published by Elsevier. The attached copy is furnished to the author for internal non-commercial research and education use, including for instruction at the authors institution and sharing with colleagues.

Other uses, including reproduction and distribution, or selling or licensing copies, or posting to personal, institutional or third party websites are prohibited.

In most cases authors are permitted to post their version of the article (e.g. in Word or Tex form) to their personal website or institutional repository. Authors requiring further information regarding Elsevier's archiving and manuscript policies are encouraged to visit:

http://www.elsevier.com/authorsrights 


\title{
Prevalence and persistence of potentially pathogenic and antibiotic resistant bacteria during anaerobic digestion treatment of cattle manure
}

\author{
Juliana Alves Resende ${ }^{a}$, Vânia Lúcia Silva ${ }^{a}$, Tamara Lopes Rocha de Oliveira ${ }^{a}$, \\ Samuel de Oliveira Fortunato ${ }^{a}$, Jailton da Costa Carneiro ${ }^{\mathrm{b}}$, Marcelo Henrique Otenio ${ }^{\mathrm{b}}$, \\ Cláudio Galuppo Diniz ${ }^{\text {a,* }}$
}

a Department of Parasitology, Microbiology and Immunology, Institute of Biological Sciences, Federal University of Juiz de Fora, 36036-900 Juiz de Fora, MG, Brazil

${ }^{\mathrm{b}}$ Embrapa Dairy Cattle, Research Center, 36038-330 Juiz de Fora, MG, Brazil

\section{H I G H L I G H T S}

- Sustainable handling of anaerobic digestion and their effluents are needed.

- Effluents from biodigesters are widely spread into land used for the agriculture.

- Putative pathogenic bacteria persist after anaerobic digestion of cattle manure.

- Antimicrobial-resistant bacteria are prevalent in the effluents from biodigesters.

- Medically important bacteria imposes sanitary risks to the anaerobic digestion.

\section{A R T I C L E I N F O}

\section{Article history:}

Received 10 October 2013

Received in revised form 29 November 2013

Accepted 3 December 2013

Available online 11 December 2013

\section{Keywords:}

Anaerobic digestion

Biogas

Biofertilizer dairy cattle manure

Antimicrobial resistance

Pathogenic bacteria

\begin{abstract}
A B S T R A C T
Anaerobic digestion figures as a sustainable alternative to avoid discharge of cattle manure in the environment, which results in biogas and biofertilizer. Persistence of potentially pathogenic and drug-resistant bacteria during anaerobic digestion of cattle manure was evaluated. Selective cultures were performed for enterobacteria (ENT), non-fermenting Gram-negative rods (NFR) and Gram-positive cocci (GPC). Antimicrobial susceptibility patterns were determined and a decay of all bacterial groups was observed after 60 days. Multidrug-resistant bacteria were detected both the influent and effluent. GPC, the most prevalent group was highly resistant against penicillin and levofloxacin, whereas resistance to ampicillin, ampicillin-sulbactam and chloramphenicol was frequently observed in the ENT and NFR groups. The data point out the need of discussions to better address management of biodigesters and the implementation of sanitary and microbiological safe treatments of animal manures to avoid consequences to human, animal and environmental health.
\end{abstract}

(c) 2013 Elsevier Ltd. All rights reserved.

\section{Introduction}

As long as the need for increased food production leads to the dairy industry growth, environmental concerns related to cattle manure management, which includes residues discharge into soil and aquatic ecosystems favoring the spread of putative pathogenic microorganisms are pointed out (Sahlström, 2003; Venglovsky et al., 2009).

In this regard, prospective studies towards new strategies for safe disposal of large quantities of cattle manure should take into

\footnotetext{
* Corresponding author. Address: Laboratory of Bacterial Physiology and Molecular Genetics, Department of Parasitology, Microbiology and Immunology, Institute of Biological Sciences, Federal University of Juiz de Fora, 36036-900 Juiz de Fora, MG, Brazil. Tel./fax: +55 3221023213.

E-mail address: claudio.diniz@ufjf.edu.br (C.G. Diniz).
}

account the sanitary and microbiological risks (Karim et al., 2005). To avoid direct discharge of manure into soil and aquatic ecosystems anaerobic digestion is pointed out as a sustainable alternative resulting in production of biogas and biofertilizer, whilst reducing the microbial load of the surrounding environments (Bagge et al., 2005; Saunders et al., 2012).

However, cattle farming is frequently referred as a reservoir for potentially pathogenic and antimicrobial resistant bacteria or also, reservoir of antibiotic resistance genes (Munir and Xagoraraki, 2011; Thames et al., 2012). To increase production related to prophylaxis, infectious diseases treatment and/or growth promoters, antimicrobial drugs are widely applied in animal husbandry (Heuer et al., 2011). As an ecological consequence, the presence of zoonotic pathogens in the environments and unintentional selection of bacteria that are resistant to antibiotics could have important human and animal health consequences, mainly when 
end up in agricultural lands (Walczak and Xu, 2011; Costa et al., 2013).

As long as anaerobic digestion has been considered an attractive method to promote a clean fuel from renewable feed stocks, such as animal manure, to develop a well-established technology, the optimization of anaerobic digestion processes requires effective operative control and possible correlation with reduction of pathogens (Holm-Nielsen et al., 2009).

In Brazil, as the most part of the country is located in the tropical region, the climatic conditions are mostly in the mesophilic range, and the majority of the anaerobic digesters are operated at ambient temperature followed by land application of the effluent (Kunz et al., 2009). In this regard, recycling of cattle manure at ambient temperature, i.e. production of energy and fertilizer from anaerobic digestion, would be of commercial and environmental interests, and no literature is available considering sanitary and ecological safety. Indeed, it is already reported concerns on the persistency of potentially pathogenic and antimicrobial-resistant bacteria during biogas and biofertilizers production, considering other anaerobic digestion models, but at constant temperatures (Beneragama et al., 2012).

In this regard, this study was focused on the evaluation of persistence of clinically relevant bacteria and their susceptibility patterns to antimicrobial drugs during anaerobic digestion effluents in continuous pilot-scale biodigesters, to accesses the sanitary risks of the process concerning human, animal and environmental health.

\section{Methods}

\subsection{Pilot-scale biogas reactor and sample collection}

Four experimental continuous biodigesters operating at ambient temperatures, with a 60 day retention time, and $60 \mathrm{~L}$ working volume were used. Fresh dairy cattle manure was collected from the experimental Embrapa dairy cattle field located in Coronel Pacheco city, Minas Gerais state, Brazil. The biodigesters was fed daily with influent of dairy cattle manure mixed with cattle wastewater (final total solids concentration 3-4\%).

Temperature was measured by using an ordinary mercury thermometer during the sampling. Total solids (TS), volatile solids (VS), and $\mathrm{pH}$ of influent and effluent samples were measured according to standard methods (APHA, 2005). Biogas produced was measured every week by gas chromatography (Agilent Technologies, 7820A). All measurements were done in triplicate and the averages were taken as representative values.

In total, 58 samples from the biodigesters were collected at different times, referred to as the influent $(n=2$, before feeding the biodigesters), and effluent ( $n=56$, samples were taken every 3-5 days during the digestion). Influent and effluent samples $(20 \mathrm{~mL})$ were collected using sterile bottles between JanuaryMarch (2012) and May-June (2012). All samples were brought to the laboratory and processed within $1 \mathrm{~h}$ after collection.

\subsection{Microbiological quantitative methods}

For bacterial counts, influent (1st day) and effluent samples (15th, 30th and 60th days) were collected and 10-fold serial diluted up to $10^{-8}$ in sterile saline solution $(0.9 \% \mathrm{NaCl})$. Aliquots of $0.1 \mathrm{~mL}$ of each dilution were submitted to selective culture in different culture medium. The lowest dilution that produced microbial counts between 20 and 200 colonies was used to estimate the number of bacteria in the samples. The Gram positive cocci Enterococcus spp. were evaluated on Bile Esculin Agar (Himedia Laboratories, India) and Staphylococcus spp. on Hypertonic Manitol Agar (Himedia Laboratories, India) after incubation at $35.5^{\circ} \mathrm{C}$ for
24 h. The Gram-negative bacteria were evaluated on Eosin-Methylene Blue Agar (Himedia Laboratories, India) after incubation at $37^{\circ} \mathrm{C}$ for $24 \mathrm{~h}$, and lactose fermenting (pink, purple or green metallic) and non-fermenting (colorless) colonies were counted. The experiments were performed in duplicates and results were expressed as mean bacterial counts.

\subsection{Isolation and identification of bacterial samples}

From the selective cultures for enterococci, staphylococci and Gram negative rods, three to five representative colonies were selected and sub-cultivated in Brain-Heart Infusion Agar (Himedia Laboratories) for stock by freezing and further experiments. For Streptococcus spp. isolation, the collected influent and effluent samples 10-fold serial diluted were streaked on sheep blood agar plates (Brain Heart Infusion supplemented with 5\% of sheep blood) and incubated in a capnophilic atmosphere $\left(5 \% \mathrm{CO}_{2}\right)$. After incubation $\left(18-48 \mathrm{~h}, 37^{\circ} \mathrm{C}\right)$, pin point white colonies were selected.

The Gram positive cocci (staphylococci, enterococci and streptococci) were presumptively identified by morphotinctorial characteristics after Gram staining, as well as the ability to hydrolyze esculin, produce catalase and presence of zone of hemolysis. Species identification was performed using the commercial system BBL Crystal Rapid Gram-Positive ID Kit (Becton \& Dickinson, USA), according to the manufacturer's instructions.

The Gram-negative bacteria were presumptively identified by morphotinctorial characteristics after Gram staining, as well as the ability of glucose, sucrose and lactose fermentation, oxidase and motility tests. Species identification was performed using API 20E (Bio Mérieux AB, Marcyl L'Etoile, France), according the manufacturer's instructions.

\subsection{Antimicrobial susceptibility assays}

The minimum inhibitory concentrations (MIC) for antimicrobial drugs were determined by the agar dilution method, according to the Clinical and Laboratory Standard Institute guideline (CLSI, 2012). Antibiotic stock solutions were added to melted MuellerHinton (Himedia) agar to obtain final concentrations ranging from 0.06 to $1024 \mu \mathrm{g} \mathrm{mL}^{-1}$. The antimicrobial drugs were selected on the basis of microbial characteristics and clinical relevance as follows: (i) for Gram positive cocci catalase-positive ( $\mathrm{GPC} / \mathrm{C}+$ ), penicillin (MedQuimica, Brazil), oxacillin (MedQuimica), vancomycin (MedQuimica), ampicillin-sulbactam (Cellofarm, Brazil), rifampin (Sigma Aldrich, USA), levofloxacin (Sigma Aldrich), trimethoprimsulfamethoxazole (MedQuimica) and erythromycin (Sigma Aldrich); (ii) for Gram positive cocci catalase-negative (GPC/C-), penicillin, vancomycin, rifampin, levofloxacin and erythromycin; (iii) for Gram negative rods Enterobacteriaceae (ENT), ampicillin (Cellofarm), ampicillin-sulbactam, piperacillin-tazobactam (Novafarma, Brazil), cefepime (Biochimico, Brazil), meropenem (Biochimico), gentamicin (Novafarma, Brazil), amikacin (Teuto-Brasileiro Laboratorio, Brazil), levofloxacin, trimethoprim-sulfamethoxazole and chloramphenicol; and (iv) for non-fermenter Gram negative rods (NFR), piperacillin-tazobactam, cefepime, gentamicin, amikacin, trimethoprim-sulfamethoxazole, meropenem, levofloxacin and chloramphenicol.

The reference strains Enterococcus faecalis ATCC 51299, Staphylococcus aureus ATCC 29213 and Escherichia coli ATCC 25922 were included as controls in the antimicrobial susceptibility assays for Gram-positive or Gram-negative bacteria and all tests were performed in duplicate. Using CLSI guidelines, the isolates were classified as sensitive, intermediate, or resistant to the tested antimicrobial agents (CLSI, 2012).

To determine the level of antibiotic resistance of the individual isolated bacteria, the multiple antibiotic resistance (MAR) index 
was calculated by dividing the number of antibiotics to which the isolate was resistant by the total number of antibiotics to which the isolates were exposed as previously described (Krumperman, 1983). A MAR value $>0.2$ was indicative of multiple antibioticresistant bacteria.

\subsection{Statistical analysis}

One-way analysis of variance (ANOVA) followed by Tukey's multiple comparisons test were applied to compare production of gas and the distribution of different bacterial groups in different biodigesters. Student's $t$-test was used for comparison of the bacterial reduction rates. The significance level was set as $p<0.05$. The microbial counts were converted to the logarithm of the number of colony forming units per $\mathrm{mL}$ of biowaste samples (log $\mathrm{CFU} \mathrm{mL} \mathrm{m}^{-1}$ ).

\section{Results and discussion}

\subsection{Pilot-scale biogas reactor performance}

Over the 60 days of hydraulic retention time in which influent of dairy cattle manure was fed, the $\mathrm{pH}$ value of the cattle manure (influent) was between 6.55 and 6.86 and ambient temperature was in the mesophilic range (between 25 and $35^{\circ} \mathrm{C}$ ). The $\mathrm{pH}$ was between 6.95 and 7.41 during the study. The percentage reduction in TS of fermenting cattle manure was about $65 \%$ and VS was $68 \%$. The average daily biogas produced was $17 \mathrm{~L} /$ day, with a methane composition above $44.06-70.27 \%$. There was no significant difference in methane composition among the pilot-scale digesters $(p=0.499)$.

Overall, there are few reports available to compare these results, considering anaerobic digestion of animal manure under ambient temperature at mesophilic range. It had already been shown that methane production by anaerobic digestion using animal manure as substrate, followed the same pattern in both mesophilic $\left(35^{\circ} \mathrm{C}\right)$ or ambient $\left(16.8-29.5^{\circ} \mathrm{C}\right.$ ) temperatures (Alvarez et al., 2006). Add to that, these data shows a similar methane production rate if compared to other studies with mesophilic bioreactors using, also, animal manure (Rico et al., 2007; Chae et al., 2008).

\subsection{Bacterial prevalence during anaerobic digestion}

The persistence of putative pathogenic bacteria such as Gram positive cocci or Gram negative rods justifies themselves the sanitary risks and microbiological relevance of the sustainable handling of anaerobic digestion and their effluents. From an ecological perspective, the occurrence of antimicrobial resistant bacteria calls to the spread and impacts of antimicrobial resistance both in human, animal and environmental health (Holm-Nielsen et al., 2009; Venglovsky et al., 2009; Costa et al., 2013).

The quantitative analysis for the viable microbial counts is presented in Fig. 1. During the experimental period, total viable count of $\mathrm{GPC} / \mathrm{C}+$ on Manitol Agar ranged from $2.65 \times 10^{5} \mathrm{CFU} \mathrm{mL}^{-1}$ in the influent ( 1 st day) to $1.57 \times 10^{3} \mathrm{CFU} \mathrm{mL}^{-1}$ in effluent after 60 days of fermentation ( $99.40 \%$ reduction, $p=7.9 \times 10^{-8}$ ). Throughout the evaluated time, decrease in $\mathrm{GPC} / \mathrm{C}+$ counts were observed between the initial load and 30 days $(p=0.0001)$, and between 30 and 60 days of anaerobic digestion $(p=0.001)$. The bacterial counts of GPC/C - on Bile Esculin Agar varied between $3.71 \times 10^{5}$ and $1.57 \times 10^{4} \mathrm{CFU} \mathrm{mL}^{-1}$ (95.76\% reduction, $p=0.0001$ ) and $\mathrm{CFU}$ reduction were observed between initial load and 15 days $(p=0.0008)$, and between 30 and 60 days of anaerobic digestion $(p=0.0495)$. The average ENT count on Eosin-Methylene Blue Agar ranged from $4.42 \times 10^{8}$ to $1.45 \times 10^{5} \mathrm{CFU} \mathrm{mL}^{-1}$, while NFR varied between $5.43 \times 10^{8}$ and $9.44 \times 10^{5} \mathrm{CFU} \mathrm{mL}^{-1}$, with average reduction of $99.96 \%\left(p=1.1 \times 10^{-11}\right)$ and $99.82 \% \quad\left(p=1.8 \times 10^{-8}\right)$, respectively. From the initial load, bacterial counts considering these microbial groups (ENT and NFR) were observed only if compared to 15 days of anaerobic digestion $\left(p=2.5 \times 10^{-12}\right.$ and $p=8.8 \times 10^{-9}$, respectively). Up to 60 days no significant bacterial counts were observed (ENT: $p=0.166$, and NFR: $p=0.152$, respectively). Overall, the reduction rates considering all the microbial groups from effluent samples were significantly different from influent samples $(p=0.029)$.

The observed GNR and enterococci densities in cattle manure (influent) were comparable to previously reported values which suggested $10^{5}-10^{8}$ fecal organisms per gram (Walczak and $\mathrm{Xu}$, 2011; Dungan et al., 2012).

The decay rate of viable bacteria after the period of anaerobic digestion of cattle manure is dependent on several factors, mainly,

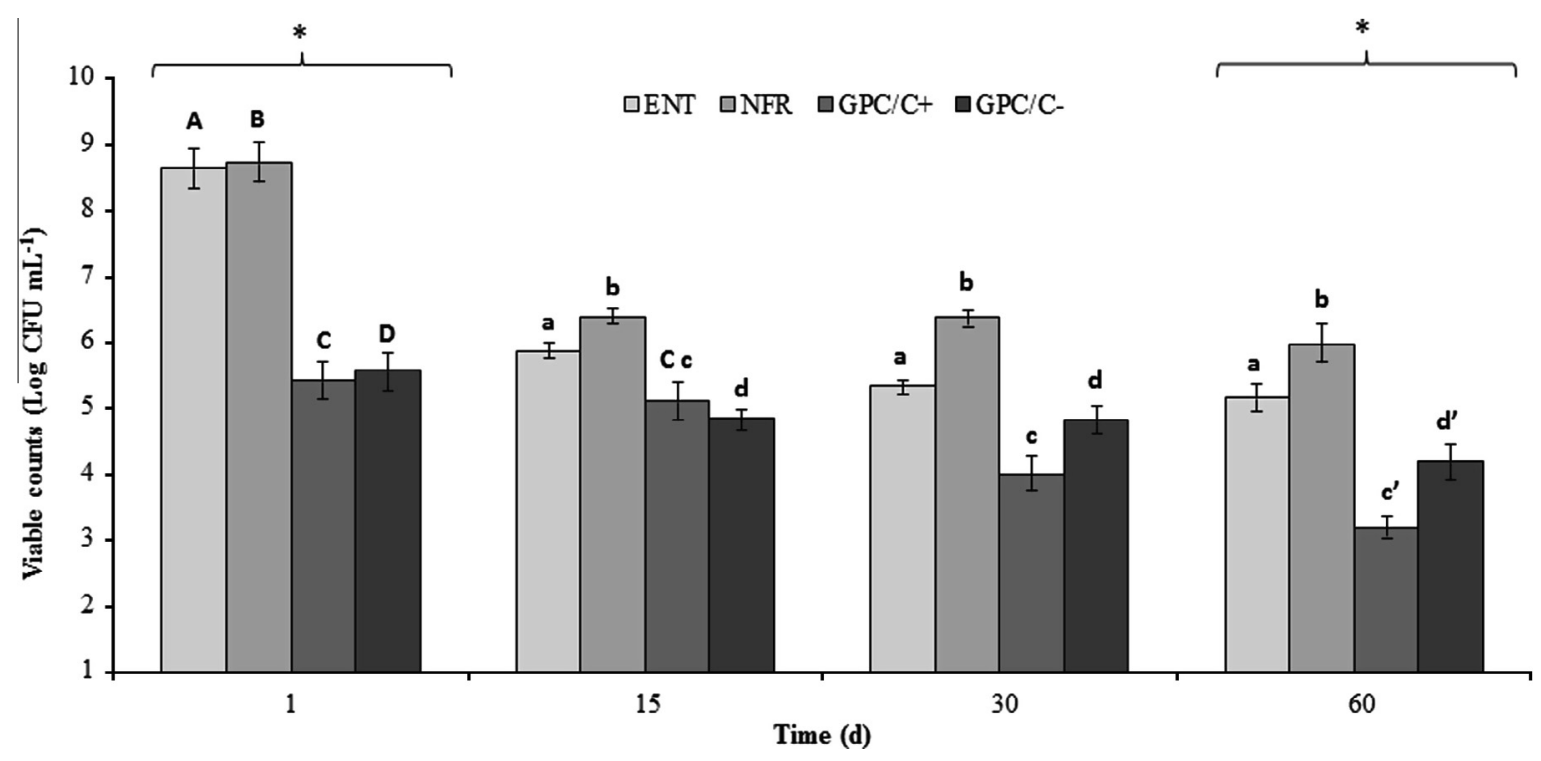

Fig. 1. Mean value of viable microbial counts ( $\log \mathrm{CFU} \mathrm{mL} \mathrm{m}^{-1}$ ) of initial load (1st day), and effluent samples (15th, 30th and 60th days), times $15-60$, from pilot-scale anaerobic digesters. ENT: Gram-negative rods from the Enterobacteriaceae family; NFR: non-fermenting Gram-negative rods; GPC/C+: Gram-positive cocci/ Catalase-positive; GPC/C-: Gram-positive cocci/ Catalase-negative. Different letters including lowercase or uppercase letters and “*” indicate statistically significant differences $(p<0.05)$. 
bacterial biology, and characteristics of anaerobic digestion including temperature and retention time (Smith et al., 2005; Pandey and Soupir, 2011). These data, together with good production rates of methane, indicate that a stable digestion process was occurring and that the digesters were achieving a performance typical of that achieved by full-scale ones. Add to that, these data are in agreement to Saunders et al. (2012) who reported increased rates of inactivation of indicator bacteria, E. coli and fecal coliform, in anaerobic digesters fed with dairy manure.

Six hundred and sixty $(n=660)$ bacterial strains were isolated from influent ( $n=67$ isolates) and effluent ( $n=593$ isolates) samples. Representative strains of GPC (staphylococci, enterococci and streptococci) were the most frequent ( $n=33,49.25 \%$; $n=353,59.53 \%)$, followed by ENT $(n=28,41.79 \% ; n=176$, $29.68 \%)$ and NFR ( $n=6,8.96 \% ; n=57,9.61 \%)$ in influent and effluent, respectively. According to ANOVA, no significant difference was observed among the sampled sites (influent and effluent) considering the variations in the same bacterial group $(p=0.093)$. Considering the frequency of microbial recovery no significant difference was found between strains (GPC, ENT and NFR) in different samples, isolates were regularly distributed $(p=0.209)$.

Microbial identification of influent samples is shown in Table 1. Out of the 33 GPC, 12 different species were identified, 36.36\% GPC/ $\mathrm{C}+$ and $63.64 \% \mathrm{GPC} / \mathrm{C}-$. The most prevalent were Enterococcus hirae

Table 1

Species distribution of bacterial strains isolated from influent samples showing the frequency of identification between Gram positive cocci (GPC) and Gram negative, as enterobacteria (ENT) and non-fermenting Gram-negative rods (NFR).

\begin{tabular}{|c|c|c|}
\hline \multicolumn{3}{|c|}{ Bacterial group (n) and frequency of species identification (\%) } \\
\hline Gram positive & Gram negative & \\
\hline GPC $(n=33)$ & ENT $(n=28)$ & NFR $(n=6)$ \\
\hline $\begin{array}{l}\text { Enterococcus hirae (15.15) } \\
\text { Enterococcus faecium (12.12) } \\
\text { Enterococcus casseliflavus/gallinarum (12.12) } \\
\text { Kytococcus sedentarius }(12.12) \\
\text { Staphylococcus capitis }(9.09) \\
\text { Staphylococcus xylosus }(9.09) \\
\text { Aerococcus viridans }(6.06) \\
\text { Enterococcus avium }(6.06) \\
\text { Enterococcus faecalis }(6.06) \\
\text { Leuconostoc citreum }(3.03) \\
\text { Leuconostoc pseudomesenteroides (3.03) } \\
\text { Micrococcus species (3.03) }\end{array}$ & $\begin{array}{l}\text { Escherichia coli }(82.14) \\
\text { Enterobacter aerogenes }(7.14) \\
\text { Enterobacter sakazakii }(7.14) \\
\text { Salmonella choleraesuis ssp (3.57) }\end{array}$ & $\begin{array}{l}\text { Ralstonia pickettii }(50.00) \\
\text { Alcaligenes faecalis }(33.33) \\
\text { Burkholderia cepacia }(16.67)\end{array}$ \\
\hline
\end{tabular}

GPC: Gram-positive cocci; ENT: Gram-negative rods from the Enterobacteriaceae family; NFR: non-fermenting Gram-negative rods.

Table 2

Species distribution of bacterial strains isolated from effluent samples showing the frequency of identification between Gram positive cocci (GPC) and Gram negative, as enterobacteria (ENT), non-fermenting Gram-negative rods (NFR) and others Gram negatives (GNR).

\begin{tabular}{|c|c|c|c|}
\hline \multicolumn{4}{|c|}{ Bacterial group (n) and frequency of species identification (\%) } \\
\hline \multirow{2}{*}{$\begin{array}{l}\text { Gram positive } \\
\text { GPC }(n=353)\end{array}$} & \multicolumn{3}{|l|}{ Gram negative } \\
\hline & ENT $(n=176)$ & NFR $(n=57)$ & Others GNR $(n=7)$ \\
\hline Enterococcus faecium (15.01) & Escherichia coli (82.95) & Alcaligenes faecalis (17.58) & Aeromonas hydrophila (100.00) \\
\hline Enterococcus hirae (12.18) & Morganella morganii (6.81) & Pseudomonas alcaligenes (17.58) & \\
\hline Streptococcus bovis (7.65) & Citrobacter freundii (2.84) & Ralstonia pickettii (10.52) & \\
\hline Aerococcus viridans (7.08) & Enterobacter asburiae (1.13) & Burkholderia cepacia (8.87) & \\
\hline Enterococcus casseliflavus/gallinarum (6.52) & Enterobacter cloacae (1.13) & Pseudomonas aeruginosa (7.01) & \\
\hline Enterococcus avium (6.52) & Providencia stuartii (1.13) & Stenotrophomonas maltophilia (7.01) & \\
\hline Staphylococcus capitis (6.52) & Raoultella terrigena (1.13) & Acinetobacter baumannii (3.50) & \\
\hline Staphylococcus xylosus (4.53) & Serratia marcescens (1.13) & Acinetobacter junii (3.50) & \\
\hline Kytococcus sedentarius (4.25) & Pantoe spp. (0.56) & Brevundimonas vesicularis (3.50) & \\
\hline Staphylococcus epidermidis (3.68) & Providencia alcalifaciens (0.56) & Pseudomonas putida (3.50) & \\
\hline Enterococcus faecalis (3.12) & Salmonella choleraesuis (0.56) & Pseudomonas stutzeri (3.50) & \\
\hline Streptococcus equinus (2.55) & & Achromobacter xylosoxidans (1.75) & \\
\hline Streptococcus salivarius (2.55) & & Acinetobacter haemolyticus (1.75) & \\
\hline Micrococcus luteus (2.27) & & Alcaligenes piechaudii (1.75) & \\
\hline Enterococcus durans (1.98) & & Moraxella osloensis (1.75) & \\
\hline Staphylococcus lentus (1.70) & & Ochrobactrum anthropi (1.75) & \\
\hline Enterococcus raffinosus (1.42) & & Pseudomonas fluorescens (1.75) & \\
\hline Pediococcus pentosaceus (1.42) & & Pseudomonas luteola (1.75) & \\
\hline Staphylococcus auricularis (1.42) & & Wautersia paucula (1.75) & \\
\hline \multicolumn{4}{|l|}{ Streptococcus criceti (1.42) } \\
\hline \multicolumn{4}{|l|}{ Streptococcus vestibularis (1.42) } \\
\hline \multicolumn{4}{|l|}{ Aerococcus urinae (1.13) } \\
\hline \multicolumn{4}{|l|}{ Staphylococcus hominis (1.13) } \\
\hline \multicolumn{4}{|l|}{ Streptococcus uberis (1.13) } \\
\hline \multicolumn{4}{|l|}{ Leuconostoc citreum $(0.85)$} \\
\hline \multicolumn{4}{|l|}{ Leuconostoc pseudomesenteroides $(0.85)$} \\
\hline \multicolumn{4}{|l|}{ Lactococcus lactis $(0.56)$} \\
\hline Kocuria varians/rosea $(0.28)$ & & & \\
\hline
\end{tabular}

GPC: Gram-positive cocci; ENT: Gram-negative rods from the Enterobacteriaceae family; NFR: non-fermenting Gram-negative rods; GNR: Gram-negatives rods. 
(15.15\%), Enterococcus faecium (12.12\%), Enterococcus casseliflavus/ gallinarum (12.12\%) and Kytococcus sedentarius (12.12\%). Out of the 34 Gram-negatives rods, $82.35 \%$ were ENT, while $17.65 \%$ were NFR. For ENT, the most prevalent species were Escherichia coli (82.14\%) and among the NFR, the most prevalent species were Ralstonia pickettii (50.00\%) and Alcaligenes faecalis (33.33\%).

The microbial identification of effluents samples is summarized in Table 2. CGP were the most observed with 28 different species identified, $25.21 \% \mathrm{CGP} / \mathrm{C}+$ and $74.78 \% \mathrm{GPC} / \mathrm{C}-$. The most prevalent were Enterococcus faecium (15.01\%), Enterococcus hirae (12.18\%) and Streptococcus bovis (7.65\%). Similar to the influent samples, Escherichia coli (82.95\%) was the most prevalent among the ENT, followed by Morganella morganii (6.81\%) and Citrobacter freundii (2.84\%). For NFR, 19 different species were observed, A. faecalis (17.58\%) and Pseudomonas alcaligenes (17.58\%) were most identified.

Enterococci and Enterobacteriaceae were the most identified microorganisms in all samples. It is known from previous studies that they are ubiquitous and potentially opportunistic pathogens. Add to that, they naturally occur in human and animal intestines and are recognized as being able to survive and to multiply under a wide range of stress conditions and hostile environments due to their high tolerance to variation of temperature and $\mathrm{pH}$ (Fisher and Philips, 2009; Costa et al., 2013). According to other previous studies, enterococci and Enterobacteriaceae populations seem to be predominant in mesophilic digesters of cattle manure (Bagge et al., 2005; Sawant et al., 2007), although the composition of microbial communities in different systems may differ due to manure handling practices and content, and environmental conditions (Sahlström, 2003).

\subsection{Antimicrobial susceptibility}

Out of 660 isolates, 239 strains (36.21\%) were resistant to at least one of the tested antimicrobials. The drug susceptibility patterns are reported in Tables 3 and 4. Considering the $\mathrm{GPC} / \mathrm{C}+$ in influent samples, the highest frequency of resistance was to penicillin (83.33\%). Antimicrobial resistance levels higher than $8.00 \%$ were observed against rifampin, erythromycin and levofloxacin. In contrast, vancomycin, ampicillin-sulbactam, oxacillin and trimethoprim-sulfamethoxazole were the most effective antimicrobials, with sensitivity rates of $100.00 \%$. For the GPC/C-, $9.52 \%$ of resistance to penicillin was observed, especially considering the enterococci strains whereas intermediate resistance was observed against rifampin (9.52\%) and erythromycin (14.28\%). Considering ENT bacteria, the highest resistance rate was observed against to ampicillin $(21.42 \%$ of resistance and $14.28 \%$ intermediate resistance). Resistance was also observed against to ampicillin-sulbactam, gentamicin and trimethoprim-sulfamethoxazole (>10\%). No antimicrobial resistance was observed against meropenem, levofloxacin and cefepime. Antimicrobial resistance was not observed among NFR strains recovered from influents samples.

With regards to bacteria isolated from effluent samples, among the 8 antibiotics tested for $\mathrm{GPC} / \mathrm{C}+$, resistance was not observed

Table 3

Drug susceptibility patterns of bacteria recovered in influent samples from pilot-scale anaerobic digesters.

\begin{tabular}{|c|c|c|c|c|c|c|c|}
\hline \multicolumn{2}{|c|}{ Microbial group and tested antimicrobial drugs } & \multicolumn{3}{|c|}{ Minimum inhibitory concentrations $\left(\mu \mathrm{g} \mathrm{mL}{ }^{-1}\right)$} & \multicolumn{3}{|c|}{ Susceptibility patterns $^{\mathrm{a}}(\%)$} \\
\hline & & $\mathrm{MIC}_{50 \%}$ & $\mathrm{MIC}_{90 \%}$ & Range & S & IR & $\mathrm{R}$ \\
\hline \multirow[t]{8}{*}{$\mathrm{GPC} / \mathrm{C}+{ }^{\mathrm{b}}$} & Rifampin & 0.06 & 0.24 & $0.06-8.00$ & 83.34 & 8.33 & 8.33 \\
\hline & Vancomycin & 0.24 & 1.00 & $0.12-2.00$ & 100.00 & - & - \\
\hline & Ampicillin-sulbactam & 0.24 & 0.50 & $0.06-4.00$ & 100.00 & - & - \\
\hline & Penicillin & 0.50 & 2.00 & $0.06-16.00$ & 16.67 & - & 83.33 \\
\hline & Erythromycin & 0.24 & 0.50 & $0.06-16.00$ & 75.01 & 16.66 & 8.33 \\
\hline & Oxacillin & 0.24 & 0.24 & $0.06-0.24$ & 100.00 & - & - \\
\hline & Levofloxacin & 0.50 & 8.00 & $0.50-16.00$ & 50.01 & 16.66 & 33.33 \\
\hline & Trimethoprim-sulfamethoxazole & 0.30 & 2.40 & $0.30-19.00$ & 100.00 & - & - \\
\hline \multirow[t]{5}{*}{$\mathrm{GPC} / \mathrm{C}-{ }^{\mathrm{c}}$} & Rifampin & 1.00 & 1.00 & $0.06-2.00$ & 90.48 & 9.52 & - \\
\hline & Vancomycin & 2.00 & 2.00 & $0.06-4.00$ & 100.00 & - & - \\
\hline & Penicillin & 0.25 & 1.00 & $0.06-32.00$ & 90.48 & - & 9.52 \\
\hline & Erythromycin & 0.06 & 1.00 & $0.06-16.00$ & 80.96 & 14.28 & 4.76 \\
\hline & Levofloxacin & 1.00 & 2.00 & $0.24-2.00$ & 100.00 & - & - \\
\hline \multirow[t]{10}{*}{$\mathrm{ENT}^{\mathrm{d}}$} & Meropenem & 0.06 & 0.06 & $0.06-1.00$ & 100.00 & - & - \\
\hline & Gentamicin & 1.00 & 64.00 & $0.25-128.00$ & 82.15 & - & 17.85 \\
\hline & Amikacin & 2.00 & 4.00 & $1.00-32.00$ & 96.43 & 3.57 & - \\
\hline & Levofloxacin & 0.06 & 0.24 & $0.06-1.00$ & 100.00 & - & - \\
\hline & Trimethoprim-sulfamethoxazole & 0.06 & 76.00 & $0.03-76.00$ & 82.15 & - & 17.85 \\
\hline & Cefepime & 0.06 & 0.12 & $0.06-1.00$ & 100.00 & - & - \\
\hline & Piperacillin-tazobactam & 2.00 & 4.00 & $1.00-32.00$ & 96.43 & 3.57 & - \\
\hline & Chloramphenicol & 4.00 & 8.00 & $4.00-32.00$ & 96.43 & - & 3.57 \\
\hline & Ampicillin-sulbactam & 4.00 & 64.00 & $1.00-128.00$ & 78.58 & 7.14 & 14.28 \\
\hline & Ampicillin & 8.00 & 32.00 & $2.00-512.00$ & 64.30 & 14.28 & 21.42 \\
\hline \multirow[t]{8}{*}{$\mathrm{NFR}^{\mathrm{e}}$} & Meropenem & 0.25 & 0.25 & $0.06-0.25$ & 100.00 & - & - \\
\hline & Gentamicin & 0.25 & 0.25 & $0.12-0.25$ & 100.00 & - & - \\
\hline & Amikacin & 0.50 & 1.00 & $0.25-2.00$ & 100.00 & - & - \\
\hline & Levofloxacin & 0.06 & 0.12 & $0.06-0.12$ & 100.00 & - & - \\
\hline & Trimethoprim-sulfamethoxazole & 2.40 & 4.80 & $0.60-38.00$ & 100.00 & - & - \\
\hline & Cefepime & 0.50 & 0.50 & $0.12-4.00$ & 100.00 & - & - \\
\hline & Piperacillin-tazobactam & 1.00 & 1.00 & $1.00-8.00$ & 100.00 & - & - \\
\hline & Chloramphenicol & 4.00 & 8.00 & $4.00-8.00$ & 100.00 & - & - \\
\hline
\end{tabular}

a S: sensitivity; IR: intermediate resistance; R: resistance.

b GPC/C+: Gram-positive cocci/Catalase-positive $(n=12)$.

c GPC/C-: Gram-positive cocci/Catalase-negative $(n=21)$.

d ENT: Gram-negative rods from the Enterobacteriaceae family $(n=28)$.

e NFR: non-fermenting Gram-negative rods $(n=6)$. 
Table 4

Drug susceptibility patterns of bacteria recovered in effluent samples from pilot-scale anaerobic digesters.

\begin{tabular}{|c|c|c|c|c|c|c|c|}
\hline \multicolumn{2}{|c|}{ Microbial group and tested antimicrobial drugs } & \multicolumn{3}{|c|}{ Minimum inhibitory concentrations $\left(\mu \mathrm{g} \mathrm{mL}^{-1}\right)$} & \multicolumn{3}{|c|}{${\text { Susceptibility patterns }{ }^{\mathrm{a}}(\%)}$} \\
\hline & & $\mathrm{MIC}_{50 \%}$ & $\mathrm{MIC}_{90 \%}$ & Range & $\mathrm{S}$ & IR & $\mathrm{R}$ \\
\hline \multirow{8}{*}{$\mathrm{GPC} / \mathrm{C}+{ }^{\mathrm{b}}$} & Rifampin & 0.06 & 1.00 & $0.06-8.00$ & 91.02 & 6.74 & 2.24 \\
\hline & Vancomycin & 0.24 & 2.00 & $0.06-2.00$ & 100.00 & - & - \\
\hline & Ampicillin-sulbactam & 0.24 & 2.00 & $0.06-16.00$ & 98.88 & 1.12 & - \\
\hline & Penicillin & 1.00 & 8.00 & $0.06-16.00$ & 25.85 & - & 74.15 \\
\hline & Erythromycin & 0.24 & 2.00 & $0.06-32.00$ & 70.79 & 19.10 & 10.11 \\
\hline & Oxacillin & 0.24 & 0.24 & $0.06-0.50$ & 91.02 & - & 8.98 \\
\hline & Levofloxacin & 2.00 & 64.00 & $0.06-64.00$ & 49.45 & 16.85 & 33.70 \\
\hline & Trimethoprim-sulfamethoxazole & 2.40 & 9.50 & $0.30-128.00$ & 95.51 & - & 4.49 \\
\hline \multirow[t]{5}{*}{$\mathrm{GPC} / \mathrm{C}_{-}{ }^{\mathrm{c}}$} & Rifampin & 0.12 & 4.00 & $0.06-8.00$ & 91.67 & 6.82 & 1.52 \\
\hline & Vancomycin & 0.50 & 4.00 & $0.06-4.00$ & 100.00 & - & - \\
\hline & Penicillin & 0.25 & 2.00 & $0.06-32.00$ & 97.35 & - & 2.65 \\
\hline & Erythromycin & 0.06 & 1.00 & $0.06-16.00$ & 85.23 & 12.50 & 2.27 \\
\hline & Levofloxacin & 1.00 & 2.00 & $0.06-4.00$ & 96.59 & 3.41 & - \\
\hline \multirow[t]{10}{*}{ ENT $^{\mathrm{d}}$ and others GNR } & Meropenem & 0.06 & 0.25 & $0.06-2.00$ & 99.45 & 0.55 & - \\
\hline & Gentamicin & 1.00 & 1.00 & $0.06-128.00$ & 99.45 & - & 0.55 \\
\hline & Amikacin & 4.00 & 4.00 & $0.25-32.00$ & 99.45 & 0.55 & - \\
\hline & Levofloxacin & 0.06 & 0.12 & $0.06-1.00$ & 100.00 & - & - \\
\hline & Trimethoprim-sulfamethoxazole & 0.06 & 4.80 & $0.06-38.00$ & 100.00 & - & - \\
\hline & Cefepime & 0.06 & 0.12 & $0.06-8.00$ & 100.00 & - & - \\
\hline & Piperacillin-tazobactam & 2.00 & 4.00 & $0.06-32.00$ & 99.45 & 0.55 & - \\
\hline & Chloramphenicol & 4.00 & 8.00 & $0.06-32.00$ & 92.90 & 4.37 & 2.73 \\
\hline & Ampicillin-sulbactam & 8.00 & 128.00 & $1.00-512.00$ & 75.96 & 7.65 & 16.39 \\
\hline & Ampicillin & 8.00 & 64.00 & $0.06-1024.00$ & 63.95 & 18.57 & 17.48 \\
\hline \multirow[t]{8}{*}{$\mathrm{NFR}^{\mathrm{e}}$} & Meropenem & 0.06 & 0.50 & $0.06-8.00$ & 96.50 & - & 3.50 \\
\hline & Gentamicin & 0.25 & 4.00 & $0.06-64.00$ & 96.50 & - & 3.50 \\
\hline & Amikacin & 1.00 & 8.00 & $0.12-128.00$ & 96.50 & - & 3.50 \\
\hline & Levofloxacin & 0.12 & 0.50 & $0.06-2.00$ & 100.00 & - & - \\
\hline & Trimethoprim-sulfamethoxazole & 9.50 & 38.00 & $0.6-304.00$ & 91.33 & - & 8.77 \\
\hline & Cefepime & 0.50 & 4.00 & $0.06-64.00$ & 96.50 & - & 3.50 \\
\hline & Piperacillin-tazobactam & 1.00 & 4.00 & $0.06-256.00$ & 98.25 & - & 1.75 \\
\hline & Chloramphenicol & 4.00 & 32 & $0.06-32.00$ & 73.69 & 7.01 & 19.29 \\
\hline
\end{tabular}

a S: sensitivity; IR: intermediate resistance; R: resistance.

b GPC/C+: Gram-positive cocci/Catalase-positive $(n=89)$.

c GPC/C-: Gram-positive cocci/Catalase-negative $(n=264)$.

d ENT: Gram-negative rods from the Enterobacteriaceae family $(n=176)$ and others GNR $(n=7)$.

e NFR: non-fermenting Gram-negative rods $(n=57)$.

against vancomycin. Penicillin was found to be the less effective drug (74.15\% resistance), followed by levofloxacin (33.70\% resistance) and erythromycin ( $10.11 \%$ resistance). In the $\mathrm{GPC} / \mathrm{C}$ - group low resistance rates were observed against rifampin, penicillin and erythromycin. Considering the Gram negative bacteria, the ENT strains were resistant only against ampicillin and ampicillin-sulbactam ( $>10 \%$ resistance), whereas for the NFR strains, antimicrobial resistance was observed against almost all the tested drugs, especially chloramphenicol (19.29\% resistance), with exception of levofloxacin, for which no resistance was observed.
The multiple antibiotic resistance (MAR) index is presented in Table 5. According to this parameter, $55.65 \%$ of the isolated bacteria is characterized as multi-resistant strains (MAR $>0.2$ ). The index ranged from 0.12 to 0.50 and 0.12 to 0.62 for GPC from influent and effluent samples respectively. Of the $\mathrm{GPC} / \mathrm{C}+$ isolated from the influent samples, $33.33 \%$ showed MAR $>0.2$, whereas considering the effluent samples, $62.92 \%$ showed MAR $>0.2$. For $\mathrm{GPC} / \mathrm{C}-, 4.76 \%$ showed MAR $>0.2$ considering the isolates from influent, whereas $2.65 \%$ of the bacteria isolated from the effluent displayed MAR $>0.2$.

Table 5

Frequency of drug-resistant bacteria and multiple antibiotic resistance (MAR) index among microbial groups isolated from pilot-scale anaerobic digesters samples.

\begin{tabular}{|c|c|c|c|c|c|}
\hline \multirow[t]{2}{*}{ Samples } & \multirow[t]{2}{*}{ Microbial group } & \multirow[t]{2}{*}{ Frequency of resistance (\%) } & \multicolumn{3}{|c|}{ MAR (frequency of determination \%) } \\
\hline & & & $<0.2$ & $>0.2$ & Range \\
\hline \multirow[t]{4}{*}{ Influent } & $\mathrm{GPC} / \mathrm{C}++^{\mathrm{a}}$ & 83.33 & 50.00 & 33.33 & $0.12-0.50$ \\
\hline & $\mathrm{GPC} / \mathrm{C}-{ }^{\mathrm{b}}$ & 28.57 & 23.81 & 4.76 & $0.12-0.25$ \\
\hline & ENT $^{\mathrm{C}}$ & 50.00 & 21.43 & 28.57 & $0.10-0.50$ \\
\hline & $\mathrm{NFR}^{\mathrm{d}}$ & 0 & 0 & 0 & 0 \\
\hline \multirow[t]{4}{*}{ Effluent } & $\mathrm{GPC} / \mathrm{C}+$ & 88.76 & 25.84 & 62.92 & $0.12-0.62$ \\
\hline & $\mathrm{GPC} / \mathrm{C}-$ & 17.42 & 14.77 & 2.65 & $0.12-0.37$ \\
\hline & ENT and others GNR ${ }^{\mathrm{e}}$ & 37.15 & 10.92 & 26.23 & $0.10-0.30$ \\
\hline & NFR & 29.83 & 15.79 & 14.04 & $0.12-0.62$ \\
\hline
\end{tabular}

a GPC/C+: Gram-positive cocci/ Catalase-positive.

b $\mathrm{GPC} / \mathrm{C}-$ : Gram-positive cocci/Catalase-negative.

c ENT: Gram-negative rods from the Enterobacteriaceae family.

d NFR: non-fermenting Gram-negative rods.

e GNR: Gram-negatives rods. 
With regards to ENT strains isolated from the influent samples, $28.57 \%$ showed MAR $>0.2$, whereas for ENT and others GNR isolated from the effluent samples, $26.23 \%$ showed MAR $>0.2$. For NFR strains isolated from the effluent samples MAR $>0.2$ was observed for $14.04 \%$ of the isolated bacteria.

Considering the purpose of anaerobic digestion effluent usage as biofertilizer in agriculture, it is important to highlight that such effluents are suitable and accepted only if the sanitary safety is satisfactorily guaranteed. Regarding pathogens, the regulations for use of manure for agricultural purposes are based on three principles: (i) a requirement for treatment, to reduce the amount of pathogens, as anaerobic digestion; (ii) confirmation of treatment; and (iii) assurance of the microbiological quality of the manure (Venglovsky et al., 2006; Martensa and Böhm, 2009). The results obtained in this study, the mesophilic anaerobic digestion of dairy manure causes a reduction of various pathogens. Although, there is another aspect to the agricultural use of effluents biodigesters, the occurrence of resistant bacteria.

In this model, as a matter of concern, an important proportion of bacteria strains recovered from the influent samples exhibited resistant to different antibiotics, and practically the same pattern of resistance was detected in effluent samples. The data show several patterns of resistance from both commensal and opportunistic pathogens which may proliferate through the environment and allow the spread of resistance genes through bacterial genetic recombination with consequences to the human and animal antimicrobial chemotherapy (Walsh et al., 2012).

A few studies have reported the prevalence of antimicrobial resistance among bacteria isolated from effluents of anaerobic digesters. Among these, back in the 80's Abdul and Lloyd (1985) reported the occurrence of resistant $E$. coli strains in mesophilic digestion at $37^{\circ} \mathrm{C}$ of pig waste. More recently, Beneragama et al. (2011) observed a persistence of drug-resistant bacteria in thermophilic co-digestion of dairy manure and waste milk at $55^{\circ} \mathrm{C}$ until the end of the process. Beneragama et al. (2012) reported a survival of multidrug-resistant bacteria in mesophilic digestion at $37^{\circ} \mathrm{C}$ of dairy manure and waste milk after 22 days of digestion, whereas no resistant-bacteria were observed after thermophilic digestion at $55^{\circ} \mathrm{C}$. These data may suggest that temperature is an important characteristic concerning drug-resistant bacteria persistence during anaerobic digestion, along with microbial completion and fermentation length.

The MAR index is widely used to refer multidrug resistant organisms in several environments. The index was introduced in 1983 and no suggestions are made regarding the minimum of antimicrobial agents in the test panel. More recently, new insights are being made regarding the definition of multidrug-resistant bacteria. For example, the definition of multidrug resistant bacteria in clinical field described by Magiorakos et al. (2012) consider oxacillin as a multiresistance marker among staphylococcal populations, when associated, especially to nosocomial environment. High frequency of MAR $>0.2$ among the bacteria isolated in the effluent samples it is reasonable to state that as it is performed, the effluent of biodigesters may play an important role as environmental reservoir of antimicrobial resistance genes. The abundance of these multidrug-resistant bacteria may reflect a microbial adaptive response to the empirical use of antimicrobials as prophylactics or therapeutics in cattle farm (Costa et al., 2013). As an ecological consequence, the adaptive mechanisms to the selective pressure imposed by antimicrobials may co-select for bacterial strategies to survive under stress conditions (Diniz et al., 2004).

Parveen et al. (2006) demonstrates regional and seasonal differences in MAR profiles among livestock farms. However, sanitary risks may become higher when antibiotic-resistant microbes are persistent along potentially pathogenic bacteria, as some species isolated in this study. These bacteria are extremely efficient in horizontal gene transfer and may contribute to the spread and maintenance of resistance genes among different bacterial populations. Considering the biofertilizer as a final product after anaerobic digestion of cattle manure, it is accepted that persistent antimicrobial-resistant bacteria may survive in the soil for up to one month after land application (Nicholson et al., 2005). In this regard, with the increasing interest for biogas production and use of effluents on arable land, becomes it import to consider the persistence of clinically important bacterial populations to sanitary safety and public health management (Bagge et al., 2005; Abubaker et al., 2012). Considering the nature of the cattle manure, it may be suggested that improvement by performing additional treatment before anaerobic digestion would interfere with initial load of methanogenic bacteria, reflecting on the biogas output, but this hypothesis was not evaluated in this study. By the other hand, it has already been reported a decay in potentially pathogenic and drug-resistant bacteria counts during thermophilic digestion (Beneragama et al., 2012). Anyway, considering the digestion at mesophilic range presented, additional steps such as effluent heating would aggregate economical costs in the final process. Other choices of post-treatment system (e.g. stabilization lagoons, ozone oxidation and anaerobic ammonium oxidation) are also suggested to efficiently remove the multidrug resistance bacteria (Berneta and Béline, 2009; Di Iaconi, 2012). Further prospective studies are needed to better discuss the extent of the antimicrobial resistance phenomena in cattle management and its consequence to the cattle manure recycling strategies with implications for human, animal and environmental health.

\section{Conclusion}

The practice of spreading of effluents from biodigesters into land used for the agriculture production is widely used. However, the presence of antimicrobial-resistant bacteria or putative pathogenic microorganisms may lead to sanitary and ecological risks. Discussions are needed concerning the use of antimicrobial drugs in animal farms and surrounding environments. Environmental regulations should address the sanitary and microbiological safety concerning the use of effluents of ambient temperature biodigesters especially regarding the persistence of putative pathogens and antimicrobial resistant bacteria.

\section{Acknowledgements}

The authors are grateful to Marlice Teixeira Ribeiro, Júnior César Fernandes, Ernando Ferreira Motta for assistance with sample collection and analysis and all students who collaborated. This study was supported by Grants from Brazilian National Council for Scientific and Technological Development (CNPq), Research Support Foundation of Minas Gerais (FAPEMIG), Coordination of Improvement of the Personnel of Higher Education (CAPES) and Embrapa Dairy Cattle.

\section{References}

Abdul, P., Lloyd, D., 1985. The survival of antibiotic resistant and sensitive Escherichia coli strains during anaerobic digestion. Appl. Microbiol. Biotechnol. 22, 373-377.

Abubaker, J., Risberg, K., Pell, M., 2012. Biogas residues as fertilisers - effects on wheat growth and soil microbial activities. Appl. Energ. 99, 126-134.

APHA, 2005. Standard Methods for Examination of Water and Wastewater, 21st ed. American Water Works Association.

Alvarez, R., Villca, S., Lidén, G., 2006. Biogas production from llama and cow manure at high altitude. Biomass Bioenerg. 30, 66-75.

Bagge, E., Sahlström, L., Albihn, A., 2005. The effect of hygienic treatment on the microbial flora of biowaste at biogas plants. Water Res. 39, 4879-4886.

Beneragama, N., Yusuke, M., Yamashiro, T., Iwasaki, M., Adekunle, L.S., Umetsu, K, 2011. The survival of cefazolin resistant bacteria in thermophilic co-digestion of dairy manure and waste milk. J. Agric. Sci. Technol., 1181-1186. 
Beneragama, N., Iwasaki, M., Lateef, S.A., Yamashiro, T., Ihara, I., Umetsu, K., 2012. The survival of multidrug-resistant bacteria in thermophilic and mesophilic anaerobic co-digestion of dairy manure and waste milk. Anim. Sci. J.. http:// dx.doi.org/10.1111/asj.12017.

Berneta, N., Béline, F., 2009. Challenges and innovations on biological treatment of livestock effluents. Bioresour. Technol. 100, 5431-5436.

Chae, K.J., Jang, A., Yim, S.K., Kim, I.S., 2008. The effects of digestion temperature and temperature shock on the biogas yields from the mesophilic anaerobic digestion of swine manure. Bioresour. Technol. 99, 1-6.

Clinical and Laboratory Standards Institute, 2012. Performance standards for antimicrobial susceptibility testing: 22nd informational supplement. Document M100-S22. CLSI, Wayne, PA

Costa, P.M., Loureiro, L., Matos, A.J.F., 2013. Transfer of multidrug-resistant bacteria between intermingled ecological niches: the interface between humans, animals and the environment. Int. J. Environ. Res. Publ. Health 10, $278-294$.

Di Iaconi, C., 2012. Biological treatment and ozone oxidation: integration or coupling? Bioresour. Technol. 106, 63-68.

Diniz, C.G., Farias, L.M., Carvalho, M.A.R., Rocha, E.R., Smith, C.J., 2004. Differential gene expression in a Bacteroides fragilis metronidazole-resistant mutant. J. Antimicrob. Chemother. 54, 100-108.

Dungan, R.S., Klein, M., Leytema, A.B., 2012. Quantification of bacterial indicators and zoonotic pathogens in dairy wastewater ponds. Appl. Environ. Microb. 78, 8089-8095.

Fisher, K., Philips, C., 2009. The ecology, epidemiology and virulence of Enterococcus. Microbiology 155, 1749-1757.

Heuer, H., Schmitt, H., Smalla, K., 2011. Antibiotic resistance gene spread due to manure application on agricultural fields. Curr. Opin. Microbiol. 14, 236-243.

Holm-Nielsen, J.B., Seadi, T.A., Oleskowicz-Popiel, P., 2009. The future of anaerobic digestion and biogas utilization. Bioresour. Technol. 100, 5478-5484.

Karim, K., Klasson, K.T., Hoffmann, R., Drescher, S.R., DePaoli, D.W., Al-Dahhan, M.H., 2005. Anaerobic digestion of animal waste: effect of mixing. Bioresour. Technol. 96, 1607-1612.

Krumperman, P.H., 1983. Multiple antibiotic resistance indexing Escherichia coli to identify risk sources of faecal contamination of foods. Appl. Environ. Microbiol. 46, 165-170.

Kunz, A., Miele, M., Steinmetz, R.L.R., 2009. Advanced swine manure treatment and utilization in Brazil. Bioresour. Technol. 100, 5485-5489.

Magiorakos, A.P., Srinivasan, A., Carey, R.B., Carmeli, Y., Falagas, M.E., Giske, C.G., Harbarth, S., Hindler, J.F., Kahlmeter, G., Olsson-Liljequist, B., Paterson, D.L., Rice, L.B., Stelling, J., Struelens, M.J., Vatopoulos, A., Weber, J.T., Monnet, D.L., 2012. Multidrug-resistant, extensively drug-resistant and pandrug-resistant bacteria: an international expert proposal for interim standard definitions for acquired resistance. Clin. Microbiol. Infect. 18, 268-281.
Martensa, W., Böhm, R., 2009. Overview of the ability of different treatment methods for liquid and solid manure to inactivate pathogens. Bioresour. Technol. 100, 5374-5378.

Munir, M., Xagoraraki, I., 2011. Levels of antibiotic resistance genes in manure, biosolids, and fertilized soil. J. Environ. Qual. 40, 248-255.

Nicholson, F.A., Groves, S.J., Chambers, B.J., 2005. Pathogen survival during livestock manure storage and following land application. Bioresour. Technol. 96, 135-143.

Pandey, P.K., Soupir, M.L., 2011. Escherichia coli inactivation kinetics in anaerobic digestion of dairy manure under moderate, mesophilic and thermophilic temperatures. AMB Express 1, 18. http://dx.doi.org/10.1186/2191-0855-1-18.

Parveen, S., Lukasik, J., Scott, T.M., Tamplin, M.L., Portier, K.M., Sheperd, S., Braun, K., Farrah, S.R., 2006. Geographical variation in antibiotic resistance profiles of Escherichia coli isolated from swine, poultry, beef and dairy cattle farm water retention ponds in Florida. J. Appl. Microbiol. 100, 50-57.

Rico, J.L., García, H., Rico, C., Tejero, I., 2007. Characterization of solid and liquid fractions of dairy manure with regard to their component distribution and methane production. Bioresour. Technol. 98, 971-979.

Sahlström, L., 2003. A review of survival of pathogenic bacteria in organic waste used in biogas plants. Bioresour. Technol. 87, 161-166.

Saunders, O., Harrison, J., Fortuna, A.M., Whitefield, E., Bary, A., 2012. Effect of anaerobic digestion and application method on the presence and survivability of E. coli and fecal coliforms in dairy waste applied to soil. Water, Air, Soil Pollut. 223, 1055-1063.

Sawant, A.A., Hegde, N.V., Straley, B.A., Donaldson, S.C., Love, B.C., Knabel, S.J., Jayarao, B., 2007. Antimicrobial-resistant enteric bacteria from dairy cattle. Appl. Environ. Microbiol. 73, 156-163.

Smith, S.R., Lang, N.L., Cheung, K.H.M., Spanoudaki, K., 2005. Factors controlling pathogen destruction during anaerobic digestion of biowastes. Waste Manage. 25, 417-425.

Thames, C.H., Pruden, A., James, R.E., Ray, P.P., Knowlton, K.F. 2012. Excretion of antibiotic resistance genes by dairy calves fed milk replacers with varying doses of antibiotics. Front Microbiol. 3, 139.

Venglovsky, J., Martinez, J., Placha, I., 2006. Hygienic and ecological risks connected with utilization of animal manures and biosolids in agriculture. Livest Sci. 102, 197-203.

Venglovsky, J., Sasakova, N., Placha, I., 2009. Pathogens and antibiotic residues in animal manures and hygienic and ecological risks related to subsequent land application. Bioresour. Technol. 100, 5386-5391.

Walczak, J.J., Xu, S., 2011. Manure as a source of antibiotic-resistant Escherichia coli and enterococci: a case study of a Wisconsin, USA Family Dairy Farm. Water, Air, Soil Pollut. 219, 579-589.

Walsh, J.J., Rousk, J., Edwards-Jones, G., Jones, D.L., Prysor Williams, A., 2012. Fungal and bacterial growth following the application of slurry and anaerobic digestate of livestock manure to temperate pasture soils. Biol. Fert. Soils 48, 889-897. 